\title{
The Novel Cucurbitaceae miRNA ClmiR86 Is Involved in Grafting-Enhanced Phosphate Utilization and Phosphate Starvation Tolerance in Watermelon
}

\author{
Weifang $W u^{1,+}$, Haoshun Zhao ${ }^{1,+}$, Qin Deng ${ }^{1,+}$, Haiyang Yang ${ }^{1}$, Xiaoxiao Guan ${ }^{1}$, Rui Qi ${ }^{1,2}$, Pibiao Shi ${ }^{1}$, \\ Jinghua Yang ${ }^{1,2,3} \mathbb{D}$, Mingfang Zhang ${ }^{1,2,3, *}$ and Zhongyuan $\mathrm{Hu}^{1,2, *}$
}

1 Laboratory of Germplasm Innovation and Molecular Breeding, Institute of Vegetable Science, Zhejiang University, Hangzhou 310058, China; 21416055@zju.edu.cn (W.W.); 22016057@zju.edu.cn (H.Z.); 21516069@zju.edu.cn (Q.D.); 21916162@zju.edu.cn (H.Y.); 22016161@zju.edu.cn (X.G.); 22016167@zju.edu.cn (R.Q.); 21316062@zju.edu.cn (P.S.); yangjinghua@zju.edu.cn (J.Y.)

2 Hainan Institute of Zhejiang University, Sanya 572025, China

3 Key laboratory of Horticultural Plant Growth, Development \& Quality Improvement, Ministry of Agriculture, Hangzhou 310058, China

* Correspondence: mfzhang@zju.edu.cn (M.Z.); huzhongyuan@zju.edu.cn (Z.H.); Tel.: +86-571-8898-2123 (M.Z.)

+ These authors have contributed equally to this work and share first authorship.

check for updates

Citation: Wu, W.; Zhao, H.; Deng, Q.; Yang, H.; Guan, X.; Qi, R.; Shi, P.; Yang, J.; Zhang, M.; Hu, Z. The Novel Cucurbitaceae miRNA ClmiR86 Is Involved in Grafting-Enhanced Phosphate Utilization and Phosphate Starvation Tolerance in Watermelon. Plants 2021, 10, 2133. https: / / doi.org/10.3390/plants10102133

Academic Editor: Abdelali Hannoufa

Received: 16 September 2021

Accepted: 5 October 2021

Published: 8 October 2021

Publisher's Note: MDPI stays neutral with regard to jurisdictional claims in published maps and institutional affiliations.

Copyright: (c) 2021 by the authors. Licensee MDPI, Basel, Switzerland. This article is an open access article distributed under the terms and conditions of the Creative Commons Attribution (CC BY) license (https:// creativecommons.org/licenses/by/ $4.0 /)$.

\begin{abstract}
Watermelon (Citrullus lanatus) is a globally important Cucurbitaceae crop in which grafting is commonly used to improve stress tolerance and enhance nutrient utilization. However, the mechanism underlying grafting-enhanced nutrient assimilation remains unclear. Here, we demonstrate the possible involvement of a novel Cucurbitaceae miRNA, ClmiR86, in grafting-enhanced phosphatestarvation tolerance via CALCINEURIN B-LIKE INTERACTING PROTEIN KINASE 5 (CICIPK5) suppression in watermelon. Transcript analyses revealed that the induction of ClmiR86 expression was correlated with the downregulation of ClCIPK5 in squash-grafted watermelon under phosphate starvation. In addition, the differential expression of ClmiR86 in various watermelon genotypes was consistent with their phosphate utilization efficiency. Furthermore, ClmiR86 overexpression in Arabidopsis enhanced root growth and phosphate uptake under phosphate starvation and promoted inflorescence elongation under normal conditions. These results suggest that the ClmiR86-ClCIPK5 axis is involved in phosphate starvation response as well as grafting-enhanced growth vigor and phosphate assimilation. The present study provides valuable insights for investigating long-distance signaling and nutrient utilization in plants.
\end{abstract}

Keywords: phosphate starvation response; phosphate utilization; grafting; watermelon

\section{Introduction}

Grafting - the unification of different parts of two or more plants that grow together and form a new plant [1] — was found to improve resistance to various biotic and tolerance of various abiotic stresses [2-5]. Watermelon (Citrullus lanatus), a popular fresh fruit, is an economically important cash crop grown globally. Grafted watermelons using squash (Cucurbita moschata) and bottle gourd (Lagenaria siceraria) as the rootstocks were first adopted in Japan in the late 1920s [6,7]. Since then, grafting has been commonly used in watermelon production to improve disease resistance, specifically against the soil-borne Fusarium wilt disease. In addition, squash grafting was found to increase nutrient uptake in watermelon [8-12].

Phosphorus is a crucial and limiting soil nutrient, and it is fundamental to plant growth, development, and propagation $[13,14]$. However, because of precipitation and mineralization, the only form of soil phosphorus that can be assimilated by plants (inorganic phosphate) for vegetative growth and development is usually scarce $[13,15,16]$. As a result, 
plants have evolved several adaptive responses, such as the expansion of the root system to accelerate soil exploration $[17,18]$, improvement of high-affinity phosphate uptake capacity [19], and production and secretion of organic acids and phosphatases to solubilize and mobilize phosphate in the soil and apoplast $[15,20]$.

miRNAs are 20-24-nucleotide single-stranded RNA molecules that inhibit gene expression at the post-transcriptional level. Several miRNAs play critical roles in diverse physiological phenomena, such as growth, development, organogenesis, and biotic and abiotic stress response [21-24]. Specifically, some miRNAs have been identified as the key players in phosphate uptake and transport in plants, such as phosphate starvation-induced miR399, miR827, and miR2111 [25-27]. In addition, phosphate starvation regulated miR156, miR778, miR828, miR169, miR395, and miR398 [25,26]. The miR399 (a-f) family was first reported to negatively regulate the expression of PHOSPHATE OVER ACCUMULATOR2 (PHO2), thereby enhancing phosphate translocation from roots to shoots [28-31]. miR399 species also acted as graft-transmissible signals under phosphate starvation, and mature miR399 was highly accumulated in OXmiR399/WT chimera roots, while the corresponding primary transcripts were absent in wildtype roots [25].

Calcineurin B-like (CBL) protein and CBL-interacting protein kinase (CIPK) complexes are well-known components of the $\mathrm{Ca}^{2+}$ signaling networks, which allow plants to finetune their responses to various stresses, such as salinity; cold; drought; and potassium, nitrate, and phosphate deficiency; these complexes are also involved in abscisic acid (ABA) signaling under stress [32-36]. For instance, CIPK3 acts as a cross-talk component between cold stress and ABA signaling [37] by physically and functionally interacting with CBL9 and forming a specific complex that functions in ABA response during seed germination [38,39]. The CBL10-CIPK24 pathway was essential for salinity tolerance by regulating $\mathrm{Na}^{+}$homeostasis in Arabidopsis [40]. CIPK23, activated by binding with CBL1 and CBL9, regulated leaf transpiration and enhanced $\mathrm{K}^{+}$uptake under potassium deficiency by phosphorylating the $\mathrm{K}^{+}$transporter [33,41,42]. A recent study revealed that CBL1-CIPK23 and CBL9-CIPK23 complexes also phosphorylated the nitrate transporter (CHL1) to maintain a low-level primary response to nitrate deficiency [43]. In Brassica napus, $B n C I P K 6$ was strongly induced by phosphate deficiency, and it functionally interacted with BnCBL1. Ectopic BnCIPK6 expression in Arabidopsis enhanced growth and biomass production under phosphate deficiency. Therefore, the BnCBL1-BnCIPK6 axis is involved in plant response to and tolerance of phosphate starvation [36]. To date, however, possible mechanisms underlying the involvement of CIPKs in phosphate starvation response and the post-transcriptional regulation of these kinases remain unknown.

Previously, we reported that phosphate uptake and utilization efficiency of squashgrafted watermelons were higher than those of self-rooted watermelons under phosphate starvation [9]. However, we did not explore the molecular effect of squash root on the phosphate starvation response of watermelon. To this end, in the present study, we demonstrated the possible involvement of a novel grafting-induced watermelon miRNA, ClmiR86, in phosphate accumulation. We also explored the expression profile of $\mathrm{ClmiR} 86$ and its respective targets (CICIPK5/AtCIPK5/AtCIPK5) under phosphate starvation in watermelon and transgenic Arabidopsis. Gene expression analysis revealed that ClmiR86 likely regulates the phosphate starvation response of squash-grafted watermelon leaves by suppressing ClCIPK5. Furthermore, ClmiR86 may be related to enhanced phosphate utilization efficiency (PUE) in watermelon. Ectopic ClmiR86 expression in Arabidopsis enhanced root growth under phosphate starvation and growth vigor during the reproductive period. Our findings provide important evidence of the role of ClmiR86 in grafting-enhanced phosphate utilization and phosphate starvation tolerance in watermelon.

\section{Results}

\subsection{ClmiR86 May Enhance PUE of Watermelon}

Our previous study demonstrated that under phosphate deficiency, phosphate uptake and PUE were significantly enhanced in squash-grafted watermelon compared with those 
in self-rooted watermelon [9]. Using small RNA deep sequencing of the same grafted watermelons, we identified ClmiR86 as a candidate long-distance signal between the scion and rootstock, since it exhibited a reverse expression pattern in these tissues after grafting. A qRT-PCR analysis confirmed that squash grafting induced and decreased ClmiR86 levels in watermelon leaves and squash roots, respectively (Figure 1A,C), indicating that ClmiR86 may be transported from the rootstock to scion. Moreover, phosphate starvation further enhanced ClmiR86 accumulation in squash-grafted watermelon leaves, but not in auto-grafted watermelon leaves (Figure 1A). Interestingly, ClmiR86 was induced by phosphate starvation in non-grafted squash roots, but not in grafted rootstock (squash root; Figure 1C), and ClmiR86 precursor showed a very similar expression profile to mature ClmiR86 in grafted watermelon leaves and squash roots under both phosphate-sufficient and phosphate-deficient conditions (Figure 1B,D). These findings indicate that ClmiR86 may act as a graft-transmissible signal (rootstock to scion) and be involved in the graftingtriggered phosphate starvation response.

A

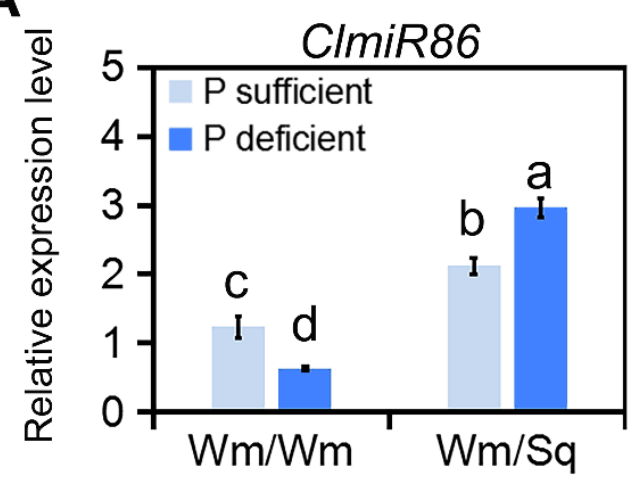

C

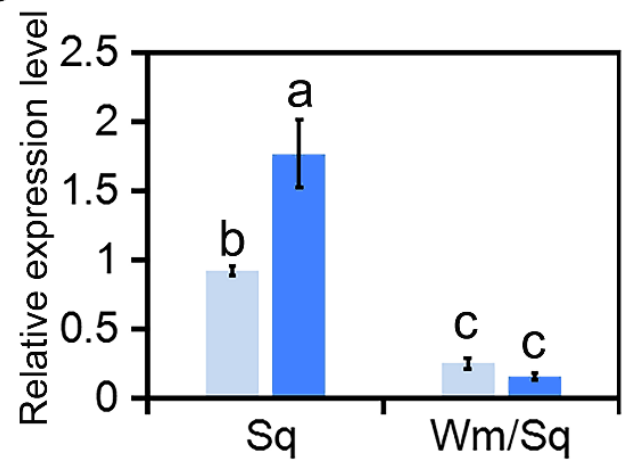

B

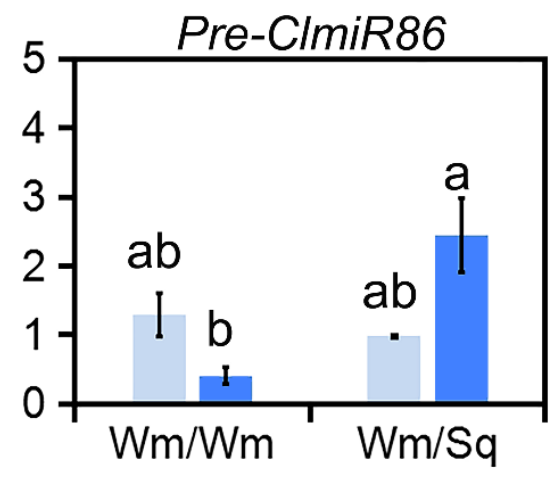

D

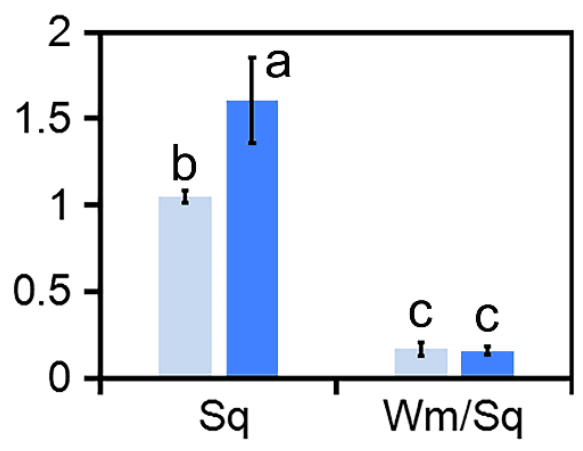

Figure 1. Grafting induced expression of ClmiR86 and Pre-ClmiR86 in watermelon leaves. Expression of (A) ClmiR86 and (B) Pre-ClmiR86 in the leaves of auto- and squash-grafted watermelon with or without $\mathrm{P}$ deficient treatment for $6 \mathrm{~h}$. "Wm/Wm" and "Wm/Sq" represent auto-, and squash-grafted watermelon (Zaojia), respectively. Expression of (C) ClmiR86 and (D) Pre-ClmiR86 in the roots of nongrafted and grafted squash roots. "Sq" and "Wm/Sq" represent non-grafted and grafted squash roots, respectively. Different lower-case letters denote a significant difference in relative expression level $(p<0.05$, one-way ANOVA and then Tukey's test for multiple comparisons). Values are means \pm SD $(n=3)$.

To investigate whether ClmiR86 accumulation is consistent with improved phosphate utilization, we tested ClmiR86 expression patterns in watermelon genotypes with different PUEs. In our previous study, ZJ, a low-PUE genotype, exhibited relatively less biomass under phosphate sufficiency and low PUE under phosphate deficiency [44]. A cyclic variation in ClmiR86 expression with photoperiod was observed in both genotypes. Phosphate deficiency slightly and transitorily enhanced ClmiR86 expression in ZJ (Figure 2A). Mean- 
while, in the high-PUE genotype XN8, ClmiR86 expression was significantly induced after $12 \mathrm{~h}$ of phosphate starvation (Figure 2B). This genotype-dependent response of ClmiR86 expression to phosphate stress indicates its possible involvement in phosphate starvation response and utilization in watermelon.

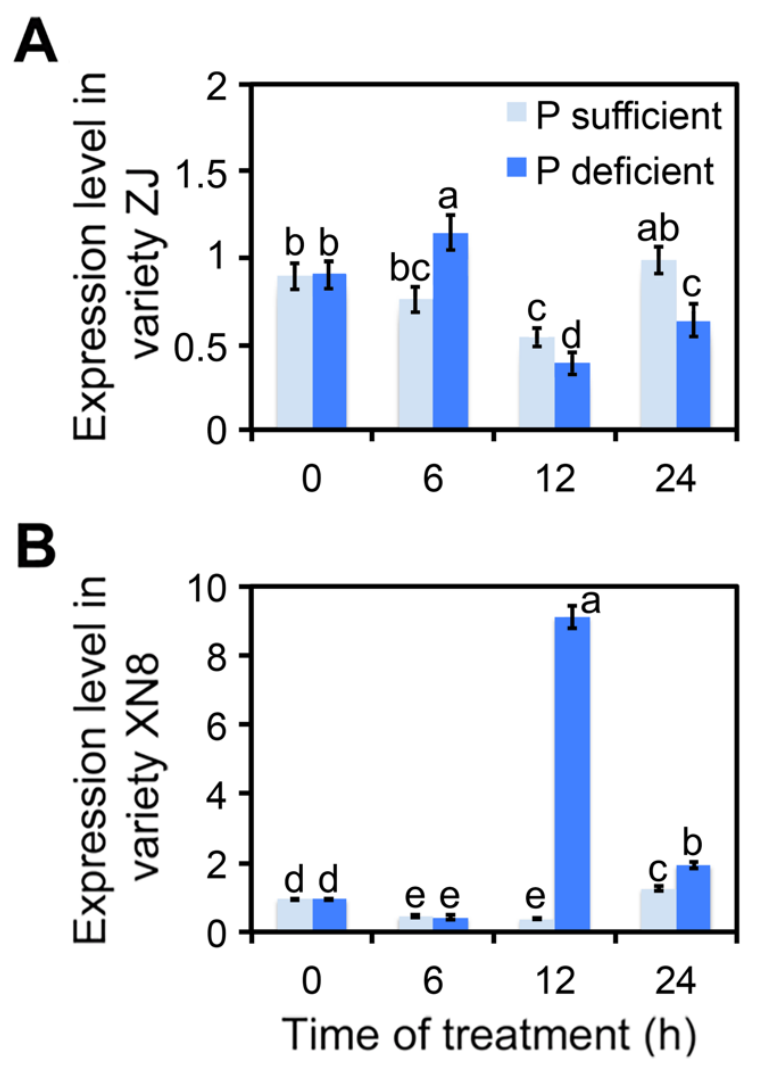

Figure 2. ClmiR86 expression varies in roots of watermelon genotypes with different $\mathrm{P}$ utilization efficiencies. Expression of ClmiR86 in the roots of (A) inefficient P utilization watermelon genotype "ZJ" and (B) efficient P utilization genotype "XN8" under different $\mathrm{P}$ concentrations. Different lowercase letters denote a significant difference in relative expression level $(p<0.05$, one-way ANOVA and then Tukey's test for multiple comparisons). Values are means $\pm \operatorname{SD}(n=3)$.

\subsection{ClmiR86 Suppresses ClCIPK5, AtCIPK5, and AtCIPK25 at the Post-Transcription Level}

miRNAs regulate the expression of target genes via binding mRNA transcripts, leading to mRNA degradation and/or translational repression. To better understand the biological functions of ClmiR86 in watermelon, the effects of grafting and phosphate deficiency were examined on the expression of ClCIPK5, a putative target gene of ClmiR86. Squash-grafting suppressed ClCIPK5 expression in watermelon leaves compared with autografting. Moreover, phosphate deficiency dramatically enhanced ClCIPK5 accumulation in auto-grafted watermelon leaves, but slightly inhibited its expression in squash-grafted watermelon leaves (Figure 3A). A similar cyclic variation in CICIPK5 expression was also observed in the two watermelon genotypes with different PUEs (Figure 3B,C). The negative correlation between $\mathrm{ClCIPK} 5$ and $\mathrm{ClmiR} 86$ expression under both grafting and phosphate deficiency indicates that squash-grafting might promote the phosphate starvation response of watermelon via the ClmiR86-ClCIPK5 axis (Figures 1 and 3). 


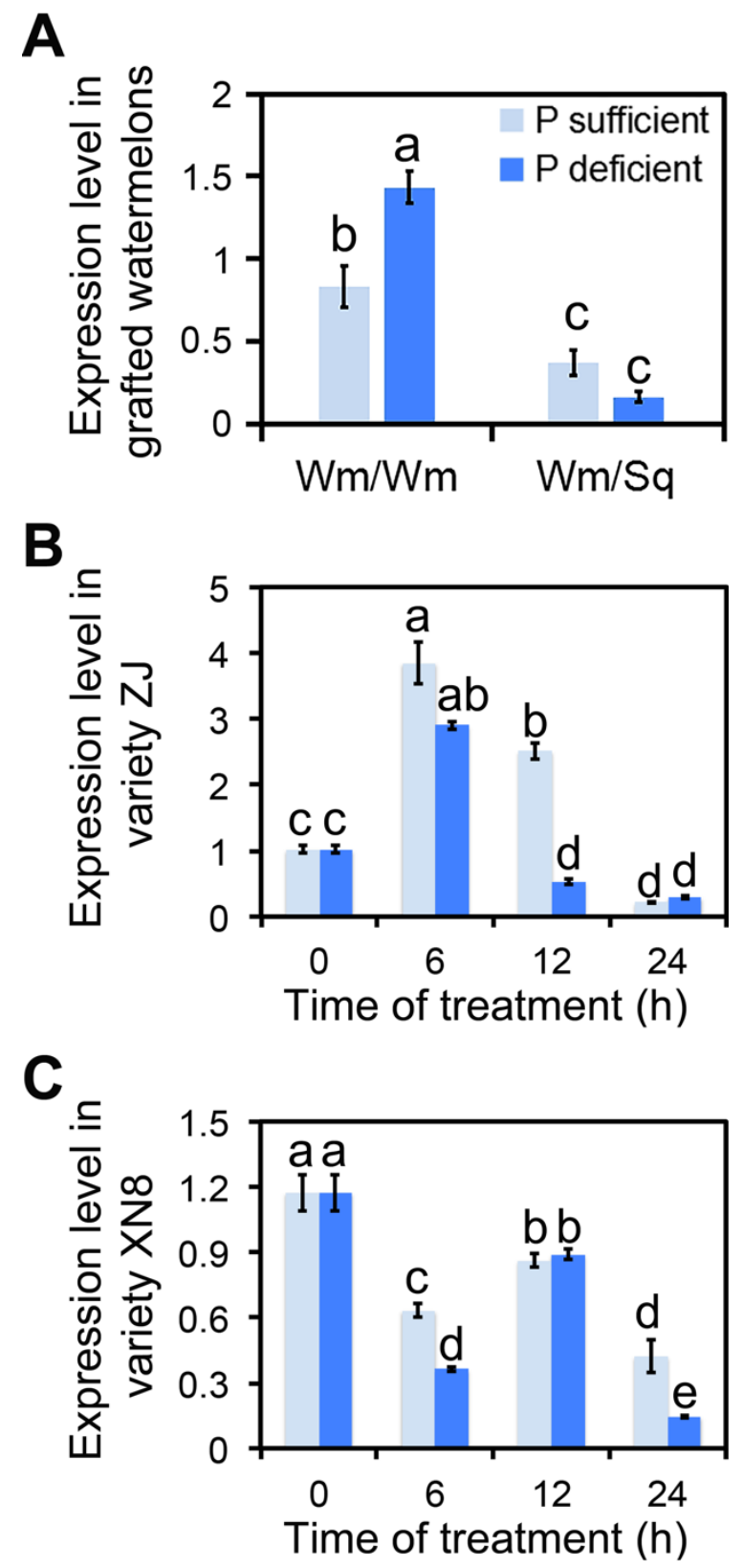

Figure 3. ClCIPK5 was regulated by grafting and phosphate deficient stress. (A) Expression of ClCIPK5 in the leaves of auto- and squash-grafted watermelon. "Wm/Wm" and "Wm/Sq" represent auto-, and squash-grafted watermelon (ZJ), respectively. (B) Expression of ClCIPK5 in the roots of inefficient $\mathrm{P}$ utilization genotype "ZJ" under different $\mathrm{P}$ concentrations. (C) Expression of ClCIPK5 in the roots of efficient $\mathrm{P}$ utilization genotype "XN8" under different $\mathrm{P}$ concentrations. Different lower-case letters indicate significant in expression level $(p<0.05$, one-way ANOVA and then Tukey's test for multiple comparisons). Values are means $\pm \operatorname{SD}(n=3)$.

To further verify the miRNA-target interaction, we also examined AtCIPK5 and AtCIPK25 expression in three independent transgenic lines (35S::ClmiR86\#2, \#3, and \#5) overexpressing the ClmiR86 precursor in the Arabidopsis Col-0 background. AtCIPK5 and AtCIPK25 were identified as the orthologous genes of ClCIPK5 in Arabidopsis (Figure 4A), and the putative ClmiR86 target site was also conserved in these two CIPKs (Figure 4B). qRT-PCR revealed a reduction in AtCIPK5 and AtCIPK25 expression in all p35S::ClmiR86 lines (Figure 4C). Interestingly, miR86 transcripts were detected in the wildtype, suggesting that this miRNA is present in Arabidopsis. These results indicate that miR86 functions may 
be conserved between watermelon and Arabidopsis via the post-transcriptional regulation of CIPKs.
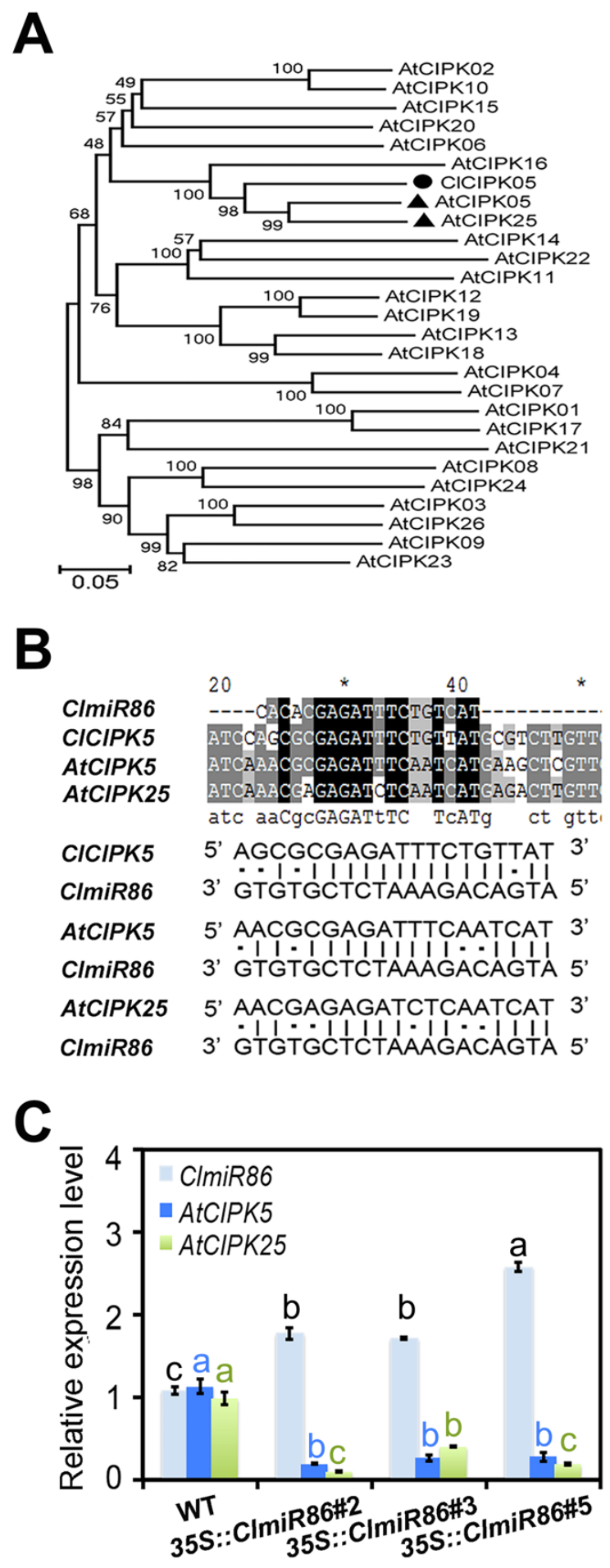

Figure 4. ClmiR86 targets the transcription of AtCIPK5 and AtCIPK25 in transgenic Arabidopsis. (A) A Neighbour-Joining tree of 26 CIPK amino acid sequences from Arabisopsis and ClCIPK5. (B) The putative ClmiR86 target site was conserved in these CIPKs. (C) The expression of ClmiR86, AtCIPK5, and AtCIPK25 in three independent transgenic lines (35S::ClmiR86\#2, \#3, \#5) over-expressing precursor of ClmiR86 in Arabidopsis Col-0 background. Different lower-case letters with same font color denote a significant difference in relative expression level of each gene $(p<0.05$, one-way ANOVA and then Tukey's test for multiple comparisons). Values are means $\pm \operatorname{SD}(n=3)$. "*" was use to show the 30th and 50th cite of the sequence respectively. 


\subsection{Ectopic ClmiR86 Expression Enhanced Phosphate Starvation Tolerance}

To gain further insight into ClmiR86 function in plants, wildtype and transgenic Arabidopsis lines overexpressing ClmiR86 were examined under phosphate starvation. No obvious phenotype was identified in transgenic plants grown under phosphate sufficiency (Figure 5A). However, 35S::ClmiR86 seedlings showed significantly increased primary root length after 1 week of phosphate starvation compared with the wildtype seedlings (Figure 5A,B). Furthermore, phosphate starvation significantly decreased lateral root number in the wildtype seedlings but did not decrease this number in 35S::ClmiR86 seedlings (Figure 5A,C). Moreover, leaf growth in both wildtype and transgenic plants were dramatically inhibited by phosphate starvation, whereas ectopic ClmiR86 expression slightly rescued leaf area under stress (Figure 5D,E). These results suggest that ClmiR86 overexpression enhances root tolerance to phosphate starvation, and this effect may be associated with its regulation of CIPKs. Interestingly, $\mathrm{PHO} 2$, a well-known phosphate starvation-responsive target of miR399, was also downregulated in 35S::ClmiR86 seedlings (Figure S1A). Moreover, pho2 mutant seedlings showed a root response similar to 35S::ClmiR86 seedlings (Figures 5 and S1).

To further verify the role of ClmiR86 in phosphate starvation response, we examined the root and inflorescence phenotypes of transgenic Arabidopsis plants under phosphate starvation at the adult stage. After 1 week, 35S::ClmiR86 plants grown under phosphate starvation showed significantly increased root tip number compared with plants grown under phosphate-sufficient conditions. Such differences were not observed in wildtype plants (Figure 6A,D). Phosphate deficiency did not affect leaf area or primary root length in any line (Figure 6B,C). When the phosphate starvation period was extended to 17 days, inflorescence length and height of wildtype plants were significantly reduced, although the flowering time remained similar among all lines. ClmiR86 overexpression evidently relieved the inhibitory effects of phosphate starvation on inflorescence elongation (Figure 6E,F). Moreover, phosphate starvation significantly decreased the phosphate levels in wildtype plants, but not in transgenic plants (Figure 6G). In addition, wildtype seedlings showed slightly lower PUE than 35S::ClmiR86 seedlings under phosphate sufficiency and phosphate deficiency slightly increased PUE (Figure 6H). These results suggest a pivotal role of ClmiR86 in phosphate signaling during root and shoot development.

A
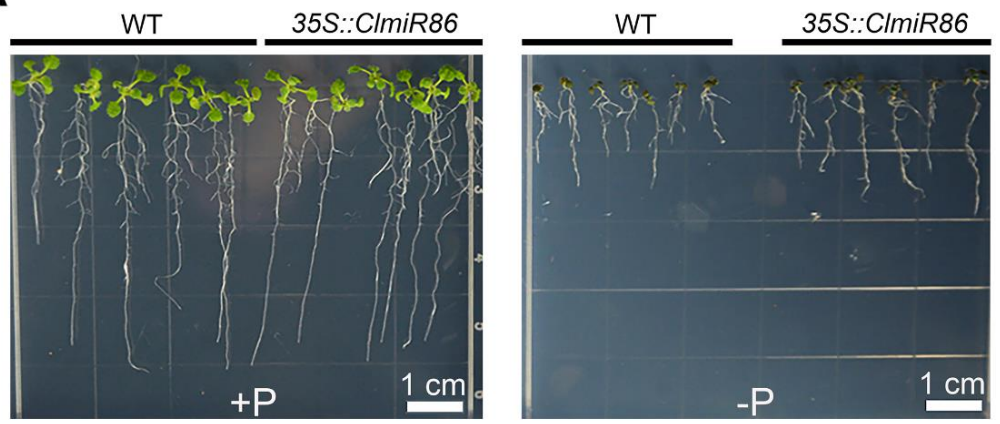

B

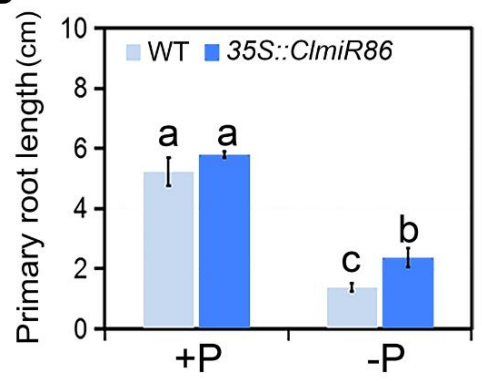

C

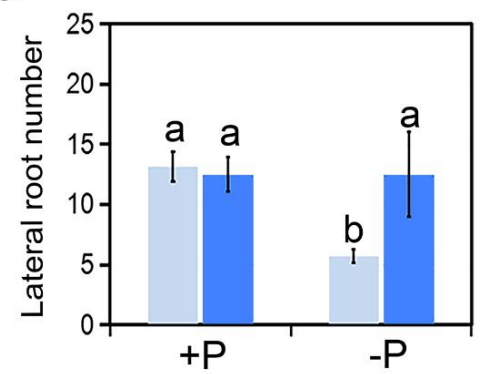

Figure 5. Cont. 

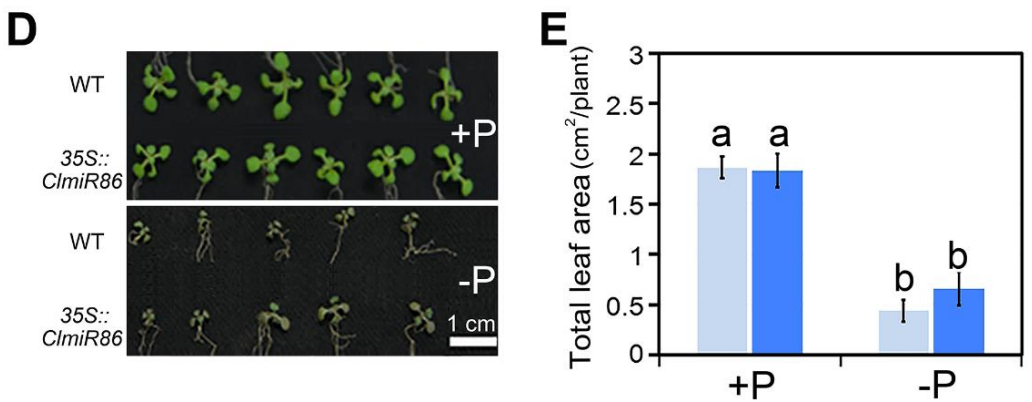

Figure 5. Ectopic expression of ClmiR86 enhanced Arabidopsis root growth under P starvation at early stage. (A) Root phenotype of wild type (WT; Col-0) and 35S::ClmiR86 Arabidopsis when grown on $+\mathrm{P}$ or $-\mathrm{P}$ MS medium for 7 days. (B) Primary root length of wild type and 35S::ClmiR86 seedlings when grown under P sufficient or deficient conditions. (C) Lateral root number of the wild type and 35S::ClmiR86 seedlings under P sufficient or deficient conditions. (D) Leaf phenotype of wild type (WT; Col-0) and 35S::ClmiR86 Arabidopsis when grown on $+\mathrm{P}$ or -P MS medium for 7 days. (E) Leaf area of the wild type and 35S::miR86 seedlings submitted to P sufficient or deficient conditions. Different lower-case letters denote a significant difference in root growth or leaf area $(p<0.05$, one-way ANOVA and then Tukey's test for multiple comparisons). Values are means \pm SD $(n=6)$.

A

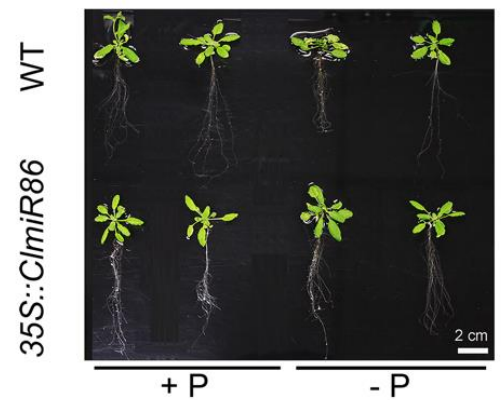

C

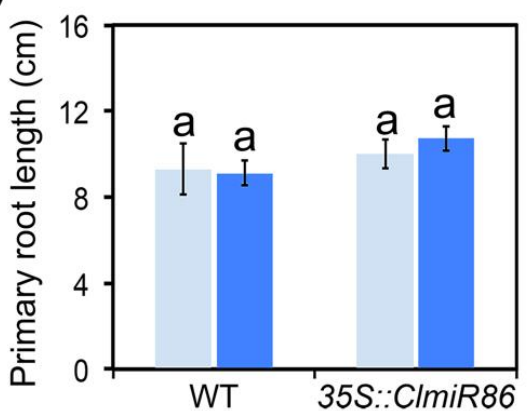

E

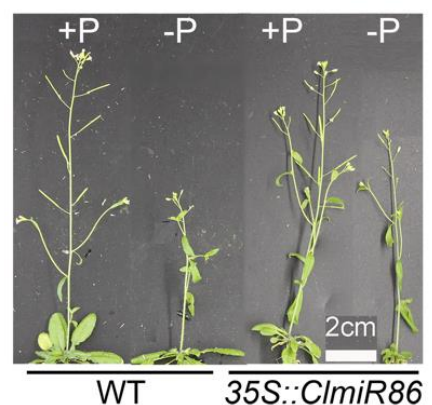

B

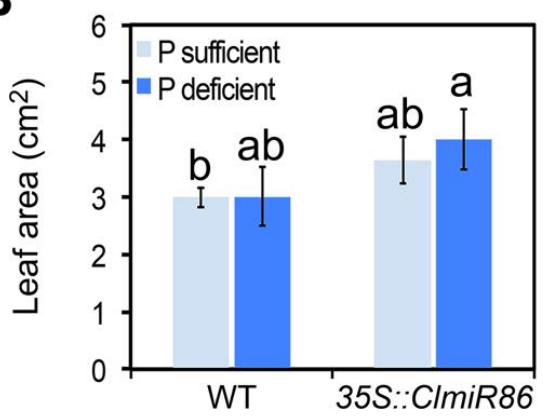

D

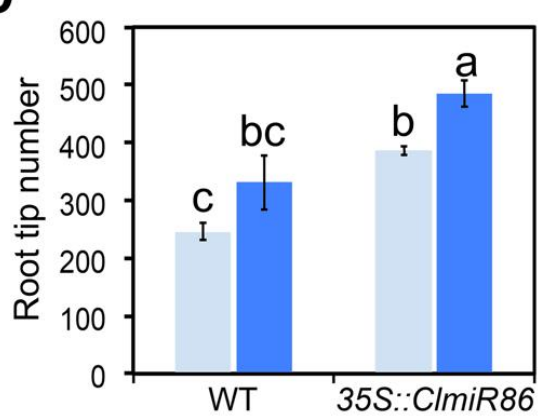

F

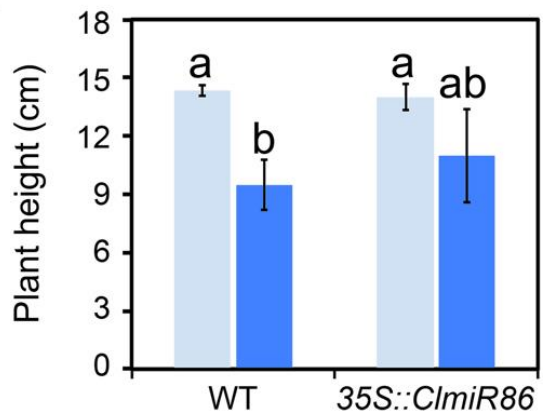

Figure 6. Cont. 
G

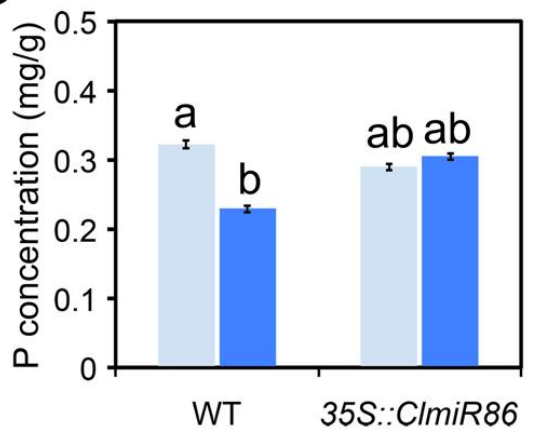

H

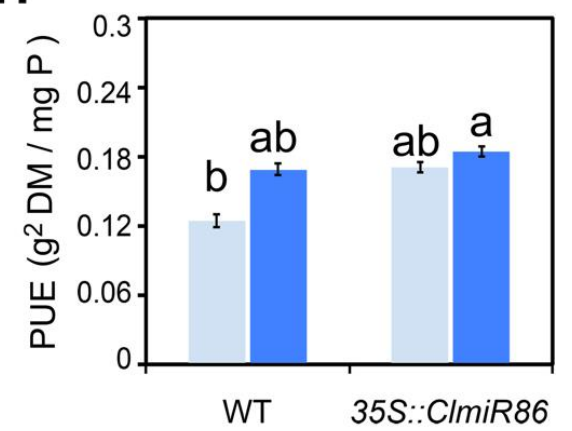

Figure 6. Phenotypes of Arabidopsis transgenic plants overexpressing ClmiR86 under P starvation conditions at adult-plant stage. (A) Arabidopsis Seedlings of wild type (WT; Col-0) and 35S::ClmiR86 in WT backgrounds were grown on Jiffy seedling culture substrate for 22 days and then transferred to hydroponic culture with one-half Hoagland solution containing $0.01 \mathrm{mM}$ P for low P treatment for additional 7 days. (B) Leaf area of the wild type and 35S::miR86 plants submitted to P sufficient or deficient conditions for 7 days. (C) Primary root length of wild type and 35S::ClmiR86 plants submitted to P sufficient or deficient conditions for 7 days. (D) Root tip number of the wild type and 35S::ClmiR86 plants submitted to P sufficient or deficient conditions for 7 days. (E) Wild type (WT) and 35S::miR86 Arabidopsis adult-plants (22-d-old) were transferred to hydroponic culture with different $\mathrm{P}$ concentrations $(0.3$ or $0.01 \mathrm{mM} \mathrm{P})$ and treated for 17 days. (F) Plant/inflorescence height of the wild type and 35S::miR86 plants submitted to P sufficient or deficient conditions for 17 days. (G) P concentration of the wild type and 35S::miR86 plants submitted to P sufficient or deficient conditions for 17 days. (H) PUE of the wild type and 35S::miR86 plants submitted to P sufficient or deficient conditions for 17 days. Different lower-case letters indicate significant difference in different plant growth parameters ( $p<0.05$, one-way ANOVA and then Tukey's test for multiple comparisons). Values are means $\pm \mathrm{SD}(n=5)$.

\subsection{Ectopic ClmiR86 Expression Enhanced Plant Growth under Normal Conditions}

To test whether the ClmiR86-ClCIPK5 signaling axis is involved in grafting-enhanced growth and phosphate assimilation in watermelon, we examined the phenotypic differences between wildtype and transgenic Arabidopsis under normal conditions. Following germination on half-strength MS medium for 4 days, 35S::ClmiR86 seeds showed a higher hulling rate than their background (Figure 7A,B), resulting in a larger leaf area in transgenic seedlings at the early stage (9 DAG) than in wildtype seedlings. However, nearly throughout the vegetative phase, no visible differences in leaf growth were observed between the transgenic and wildtype seedlings (Figure 7C). Interestingly, 35S::ClmiR86 plants exhibited more vigorous growth than wildtype seedlings after they reached the generative phase (29-30 DAG), resulting in a larger photosynthetic area and longer inflorescence (Figure 7C,D). To establish a link between ClmiR86-ClCIPK5 signaling and enhanced PUE, we analyzed the expression of 12 phosphate transporter genes (PHTs) using qRT-PCR. Transcripts of several of these genes were upregulated in ClmiR86-overexpressing lines compared with in wildtype seedlings (Figure S2B). Three CBL genes, namely AtCBL1, AtCBL3, and AtCBL4, interact with CIPK5 [45]. AtCBL1 and AtCBL4 expression was clearly increased in ClmiR86-overexpressing lines, perhaps due to feedback regulation (Figure S2C). These results indicate that ClmiR86 overexpression promoted plant growth under normal conditions, which is likely related to enhanced phosphate transport via altered CIPK-CBL signaling. 
A
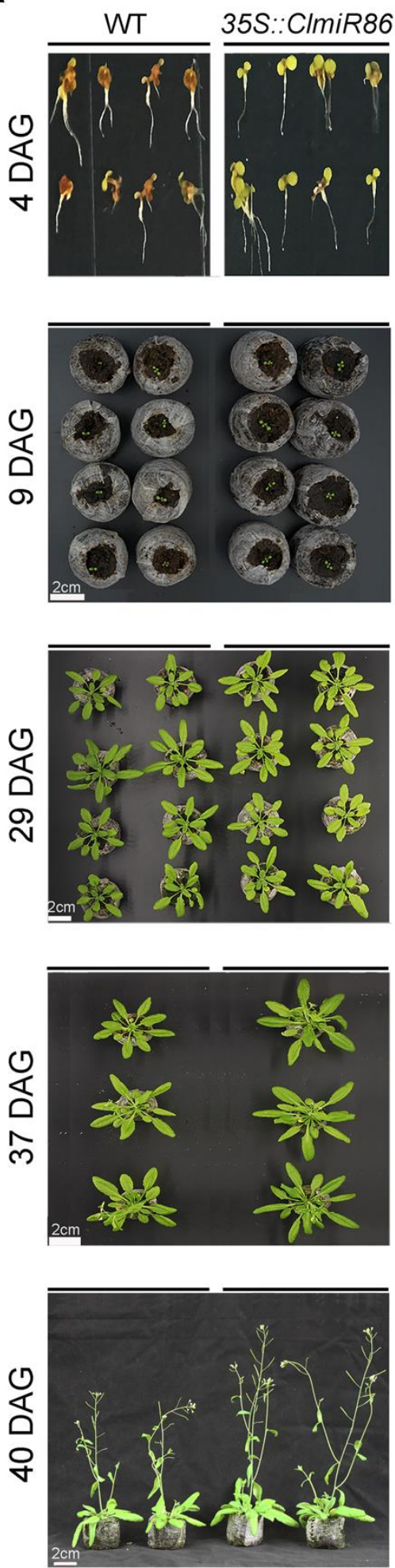

B

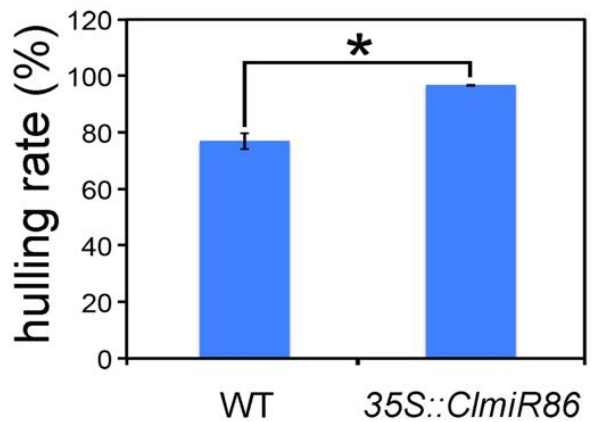

C

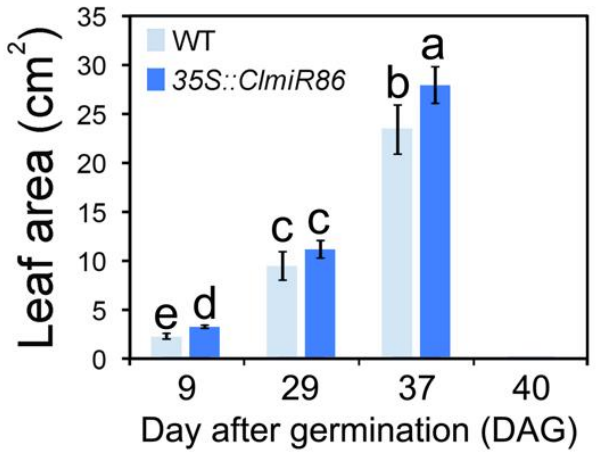

D

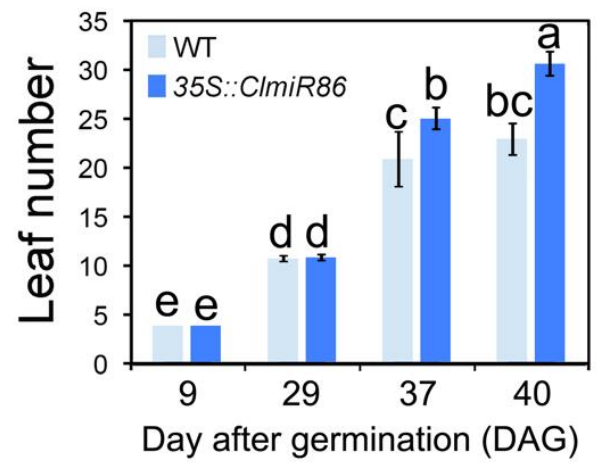

E

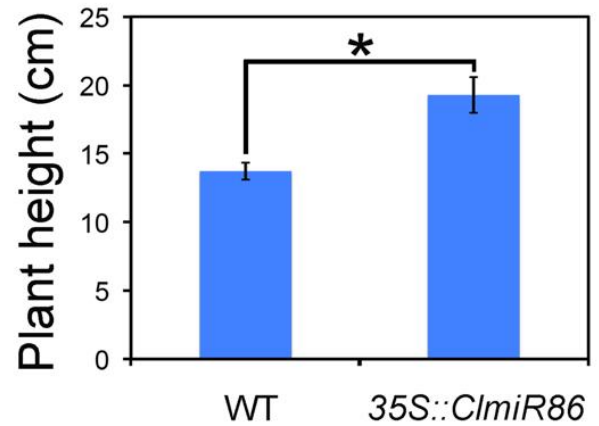

Figure 7. Ectopic expression of ClmiR86 enhanced plant growth under normal conditions. (A) Phenotype of wild type (WT) and 35S::miR86 seedlings at 4, 9, 29, 37, and 40 day-after-germination (DAG). (B) Hulling rate of Arabidopsis seeds at 4 DAG age. (C) Average leaf area of Arabidopsis seedlings at different Age. (D) Average leaf number of Arabidopsis seedlings at different DAG age. (E) Plant/inflorescence height of Arabidopsis seedlings at 40 DAG age. Asterisk $\left({ }^{*}\right)$ or different lowercase letters indicates significant difference in hulling rate, leaf area and number, or plant height $(p<0.05$, one-way ANOVA and then Tukey's test for multiple comparisons). Values are means \pm SD $(n=10)$. 


\section{Discussion}

Grafting has been adopted as one of the most effective techniques for improving plant stress tolerance and modifying ion accumulation in a number of plant species [2,12,46]. It is also commonly used in horticultural crops to increase nutrient uptake and utilization, which reduces not only crop production costs, but also global environmental pollution. Here, we demonstrated the possible role of ClmiR86, a novel Cucurbitaceae miRNA, as a positive regulator of phosphate deficiency tolerance and grafting-enhanced phosphate utilization in watermelon.

\subsection{Squash Grafting Enhanced Watermelon Phosphate Utilization}

Watermelon is one of the most important economic crops in the world. Squash is commonly used as a rootstock for watermelon grafting, leading to greater production and stronger resistance/tolerance to various stresses. In several studies, squash grafting was found to increase iron, nitrate, potassium, calcium, or magnesium ion concentration in watermelon [8,10-12]. In addition, we previously demonstrated enhanced phosphate assimilation with squash grafting [9]. However, the effects of rootstock and scion on each other and their overall effects on nutrient absorption remain largely unknown. Typically, modification of the root architecture is a popular means of enhancing ion uptake, accumulation, and utilization efficiency. Indeed, the squash rootstock has a vigorous root system, with more lateral roots and root hair, higher total root length, and greater root surface area than watermelon. The root dry weight of pumpkin-grafted watermelon was 2.24 higher than that of self-rooted plants [47]. Some plant metabolites, including sugars, hormones, and miRNAs, may function as long-distance signaling molecules and regulate ion uptake and/or homeostasis by affecting the activity of ion transporters. Unfortunately, research on ion transporters and miRNA-regulated nutrient uptake has focused on model and non-grafted plants, and information on grafted horticultural crops is limited. In the present study, the link between squash grafting-enhanced phosphate utilization and ClmiR86 accumulation (Figure 1; [9]) provided an important clue for elucidating the mechanism of grafting-enhanced abiotic stress tolerance and developing improved nutrient-efficient rootstocks.

\subsection{ClmiR86 Is Involved in Phosphate Starvation Response and Phosphate Utilization in Watermelon}

The roles of miRNAs in nutrient acquisition, transport, and homeostasis have been summarized in the literature [27,48]. Some miRNAs (e.g., miR160, miR167, miR393, miR171, and miR3979) have been proposed to play roles in nitrate uptake, possibly by promoting or suppressing root functions (primary root elongation and lateral or adventitious root emergence) [49-52]. miR169, miR156, and miR826/miR5090 affect nitrate uptake, metabolism, and consumption [53-55]. In addition, miR444, which targets MADS23, may be involved in nitrate and potassium uptake or translocation from old to young leaves [27,56]. Recently, miR399 and miR827 were demonstrated to be important for the phosphate starvation response, as they inhibit genes involved in PHT1 and PHO1 suppression, contributing to their accumulation under stress [25-27]. PHT1 proteins can use energy to cotransport Pi and $\mathrm{H}^{+}$ions and are therefore involved in inorganic phosphate acquisition [57]. PHO1 is involved in the loading of the acquired inorganic phosphate into the xylem and facilitating the root-to-shoot transport of this macronutrient in plants [58,59]. The miR399-PHO2 and miR827-NLA pathways are likely coordinated to allow for fine-tuning of the expression of the high-affinity Pi transporter PHT1 for maintaining phosphate homeostasis [27,60-62]. Here, we reported the novel watermelon miRNA ClmiR86, which was induced by grafting and phosphate deficiency (Figures 1 and 2). Ectopic expression of this miRNA in Arabidopsis enhanced phosphate deficiency tolerance based on its promoting effect on primary root elongation and lateral root emergence (Figure 5). miR86 function may be conserved between watermelon and Arabidopsis, as mature miR86 was also detected in wildtype Arabidopsis plants (Figure S2A). Interestingly, this root phenotype was similar 
to that of the phosphate-over-accumulating mutant pho2 grown under the same conditions (Figure S1), suggesting that ClmiR86-triggered phosphate deficiency tolerance is due to enhanced phosphate assimilation. In addition, the expression of several phosphate acquisition-related genes was affected in transgenic Arabidopsis seedlings (Figure S2B), similar to that in the pho2 mutant [62], suggesting that ClmiR86 is involved in phosphate signaling via the functions of these genes.

Squash grafting enhanced ClmiR86 accumulation in scion leaves compared with autografting (Figure 1A), which is consistent with the results observed by Liu et al. [1] that grafting altered miRNA expression levels in the leaves of pumpkin-grafted watermelon seedlings. In addition, our findings implied that ClmiR86 might act as a graft-transmissible signal exported from the squash rootstock to watermelon leaves or reverse responses to both squash grafting and phosphate deficiency in leaves and roots (Figure 1). Similarly, Li et al. [63] showed that the expression of some miRNAs in the leaves and roots differed between pumpkin- and auto-grafted cucumbers as well as between seedlings grown under nitrate and phosphate deficiency. Among these, the expression levels of miR399 and csa$m i R-n 08$ were increased in leaves, but decreased in the roots of pumpkin-grafted cucumber seedlings compared with those of auto-grafted seedlings. The altered miRNA levels then affected the expression of MYB transcription factors, including phosphate starvation regulator 1 (PHR1), phosphate starvation regulator 1-like (PHR1-LIKE1), and E3 (ubiquitin-protein ligase) in cucumber, which are essential for phosphate absorption [63]. Similar response patterns of ClmiR86 and csa-miR-n08 to both grafting and phosphate deficiency in scion and rootstock indicate shared or conserved regulatory network in squash-grafted watermelon and cucumber under phosphate starvation.

\subsection{CIPK5 Works Downstream of ClmiR86 under Phosphate Starvation and Normal Conditions}

In plants, the CBL-CIPK signal components form a complex signaling network, which allows for flexible but specific signal-response coupling during adaptation to environmental stresses and nutrient deficiency [64]. The CBL-CIPK pathways have been reported to function as nutrient transport and homeostasis regulatory networks in response to low potassium [65,66], sodium [41,42], magnesium [67], nitrate [43,68], and phosphate [36]. In the present study, watermelon CIPK5 was found to be involved in early phosphate signaling, and ClCIPK5 transcript levels were rapidly decreased by squash grafting (Figure 3 ). In addition, ClmiR86 overexpression significantly decreased AtCIPK5 and AtCIPK25 (orthologs of ClCIPK5) expression, perhaps due to enhanced plant tolerance to phosphate deficiency (Figures 4-6). Recently, Brassica napus CIPK (BnCIPK6) was also found to be involved in the phosphate starvation response. BnCIPK6 expression was strongly induced by phosphate deficiency, and transgenic Arabidopsis seedlings overexpressing BnCIPK6 grew better than the wildtype ones under phosphate starvation [36]. These results suggest a positive function of CIPK in phosphate deficiency tolerance, contrary to that of ClCIPK5. Orthologous genes of BnCIPK6 in Arabidopsis and chickpea (AtCIPK6 of CaCIPK6) were found to affect lateral root formation and salinity tolerance, possibly via their function in auxin transport and sensitivity, highlighting the role of CIPKs in root development [69]. This is partly consistent with our findings that reduced ClCIPK5 transcript levels in transgenic Arabidopsis may result in significant lateral root differences (Figures 5 and 6). A recent study indicated that the CIPK23-CBL9 complex could regulate primary nitrate responses via its phosphorylation function on the dual-affinity nitrate transporter CHL1 [43]. Of note, even though no functional analysis of CIPK5 or CIPK25 has been performed in Arabidopsis, CIPK5 was found to weakly interact with CBL1 in a yeast two-hybrid system [70]. This finding indicates a possible indirect interaction between CIPK5 and CIPK23 during complex formation as well as a cross-talk between nitrate and phosphate starvation responses. Unfortunately, the downstream substrates of CIPK6, CIPK5, or CIPK25, which might directly affect phosphate sensing or transport, have not been identified. Knowledge of these substrates will become a critical piece for solving the jigsaw puzzle of plant phosphate starvation responses. Thus, the CIPK5 downstream substrates mediating interaction with 
CBL must be identified to unveil the mechanism of grafting-triggered phosphate deficiency tolerance and phosphate assimilation.

In conclusion, we identified a novel grafting-induced or grafting-transportable miRNA in watermelon. ClmiR86 likely targets the transcripts encoding CIPK5 and CIPK25, which are involved in phosphorus sensing or stress signaling. Plants overexpressing ClmiR86 showed decreased expression of the target CIPK genes, enhanced lateral root growth under phosphate deficiency, and increased growth vigor under normal conditions. These findings provide valuable clues to further explore the mechanism of grafting-enhanced stress tolerance and nutrient utilization.

\section{Materials and Methods}

\subsection{Plant Materials, Growth Conditions, and Treatments}

The watermelon cultivar 'Zaojia' (ZJ) was grafted onto the squash cultivar 'Feichangfuzuo' $(\mathrm{Wm} / \mathrm{Sq})$ and watermelon $(\mathrm{Wm} / \mathrm{Wm})$. Self-rooted squash plants were used as controls for squash roots. Two watermelon genotypes, namely 'Xinong 8 Hao' (XN8) and ZJ, with different PUE were used to characterize the genotypic variations in ClmiR86 and ClCIPK5 expression [9]. Following seed germination, all watermelon and squash seedlings were grown in the Professional Growing Mix (Fafard ${ }^{\circledR} 51$ L Mix). Grafting was performed when the scion and rootstocks were at the cotyledon stage and one-leaf-stage, respectively. All plants were cultivated in a growth chamber under photosynthetically active radiation at $28^{\circ} \mathrm{C}$ (day) $/ 24^{\circ} \mathrm{C}$ (night) under a $16 \mathrm{~h} \mathrm{light} \mathrm{period} \mathrm{at} \mathrm{an} \mathrm{intensity} \mathrm{of} 600 \mu \mathrm{mol} \cdot \mathrm{m}^{-2} \cdot \mathrm{s}^{-1}$ and $50-85 \%$ humidity. Phosphate starvation treatments were performed until the grafted plants and the two watermelon genotypes reached the two-true-leaf stage.

Under phosphate deficiency stress, all watermelon seedlings were transferred to hydroponic growth containers with full-strength Hoagland solution $(0.3 \mathrm{mM}$ phosphate; PH 6) and acclimated for 3 days. The seedlings were then subjected to phosphate starvation $(0.01 \mathrm{mM})$ (Table S1). After $6 \mathrm{~h}$ of treatment, the grafted watermelon leaves and squash roots were collected. Root samples were also harvested from XN8 and ZJ at specific time intervals $(6,12$, and $24 \mathrm{~h})$. All samples were stored at $-80^{\circ} \mathrm{C}$ for further assays.

Seeds of Arabidopsis pho 2 mutants were kindly provided by Professor Huixia Shou (Zhejiang university, China) [71]. Arabidopsis thaliana ecotype Columbia-0 (WT) was used to generate ClmiR86 overexpression lines (35S::ClmiR86). For growth and development studies, WT and 35S::ClmiR86 Arabidopsis seeds were sown on the Jiffy seedling culture substrate, stratified at $4{ }^{\circ} \mathrm{C}$ for 3 days and then grown in growth chambers (Sanyo; http: / / www.sanyobiomedical.co.uk, accessed on 3 September 2021) at $22^{\circ} \mathrm{C}$ under a $16 \mathrm{~h}$ photoperiod at $200 \mu \mathrm{mol} \cdot \mathrm{m}^{-2} \cdot \mathrm{s}^{-1}$ light intensity and $60 \%$ relative humidity. Rosette leaf samples were collected and stored at $-80^{\circ} \mathrm{C}$ for further assays.

For the Arabidopsis phosphate starvation experiment at the seedling stage, WT and 35S::ClmiR86, pho2 mutant seeds were surface sterilized twice with $20 \%(v / v)$ bleach for $1 \mathrm{~min}$. After washing three times with sterile distilled water, the seeds were cultured in phosphate-sufficient $\left(\mathrm{P}^{+}\right)$medium containing half-strength MS medium (PhytoTechnology Laboratories), $1 \%(w / v)$ sucrose, and $1.2 \%(w / v)$ agar; vernalized at $4{ }^{\circ} \mathrm{C}$ for 3 days; and grown vertically in a growth chamber for 1 week (Sanyo). Thereafter, some 1-weekold plants were transferred onto a phosphate-deficient $\left(\mathrm{P}^{-}\right)$medium, in which $1.25 \mathrm{mM}$ $\mathrm{KH}_{2} \mathrm{PO}_{4}$ in the $\mathrm{P}^{+}$medium was replaced with $0.65 \mathrm{mM} \mathrm{K}_{2} \mathrm{SO}_{4}$, while the remaining plants grown on $\mathrm{P}^{+}$and half-strength MS medium as the controls (Table S2). After 1 week of culture, leaf area, primary root length, and lateral root number were measured and photographed. Six seedlings were measured for each treatment, and three biological replicates were performed.

For Arabidopsis hydroponic culture at the adult stage, WT and 35S::ClmiR86 Arabidopsis adult-plants (22-day old) were transferred to hydroponic culture with half-strength Hoagland solution containing $0.3 \mathrm{mM}$ phosphate for additional 7 or 17 days. Phosphate starvation was initiated by replacing $0.3 \mathrm{mM}$ phosphate with $0.01 \mathrm{mM}$ phosphate (Table S1). 


\subsection{Vector Construction}

To generate 35S::ClmiR86 Arabidopsis lines, a 272 bp fragment containing the ClmiR86 precursor foldback structure was amplified using total RNA extracted from watermelon leaves with the primer pair Pre-miR86-F and Pre-miR86-R; cloned into pDONR221 (Invitrogen); and recombined into the GatewayTM vector pMDC83 binary expression vector under the control of the CaMV $35 S$ promoter using the Gateway cloning system [72]. The primers used for vector construction are shown in Table S3.

\subsection{Arabidopsis Transformation}

The ClmiR86-pMDC83 construct was introduced into Agrobacterium tumefaciens strain GV3101. Wildtype Arabidopsis was transformed using the floral dip method [73]. To screen for transgenic plants, seeds harvested from transformed Arabidopsis plants were germinated on MS medium containing $50 \mu \mathrm{g} \cdot \mathrm{mL}^{-1}$ hygromycin B (Roche, http:/ /www.roche.com; accessed on 10 September 2021 ), vernalized at $4{ }^{\circ} \mathrm{C}$ for 3 days, and incubated in a growth chamber (Sanyo) for 10 days. The 10-day-old hygromycin B-resistant plants were then transferred to the Jiffy seedling culture substrate. PCR and quantitative real-time PCR (qRT-PCR) of ClmiR86 in candidate transgenic Arabidopsis plants were used to confirm the success of transformation (Figures S1 and S2A). WT and T3 plants were used in the present study. All primers used for the confirmation of Arabidopsis transformation are listed in Table S3.

\subsection{Target Gene Prediction}

The ClmiR86 mature sequence was used as the query to search for putative targets against the watermelon (ICuGI; http://www.icugi.org/cgi-bin/ICuGI/index.cgi; accessed on 10 September 2021 ) and Arabidopsis (TAIR; http:/ / www.arabidopsis.org; accessed on 10 September 2021 ) databases with TagetFinder 1.6. To detect whether the target sites were conserved in Arabidopsis, the coding sequences of ClCIPK5, AtCIPK5, and AtCIPK25 in the genomes of watermelon and Arabidopsis were retrieved from the ICuGI and TAIR databases, respectively. A multiple sequence alignment of the nucleotide sequences of CIPKs (ClCIPK5, AtCIPK5, and AtCIPK25) and ClmiR86 was performed using ClustalX 2.0 with default settings, as described by Thompson et al. [74].

\subsection{Phylogenetic Tree Construction}

To identify the orthologous genes of ClCIPK5 in Arabidopsis, the amino acid sequences of 26 CIPKs in the genome of Arabidopsis were retrieved from the TAIR database (http:/ / www.arabidopsis.org; accessed on 10 September 2021 ). A neighbor-joining tree based on the protein sequence alignments was constructed using MEGA 6.0, with 1000 bootstrap replicates.

\subsection{PUE Measurement}

Shoots of the WT and 35S::ClmiR86 seedlings grown in either $\mathrm{P}^{+}$or $\mathrm{P}^{-}$medium or soil were sampled separately. Phosphate levels were measured using the vanadium-molybdenum method [75]. PUE was calculated as plant total dry weight divided by phosphate levels [76].

\subsection{RNA Isolation, $c D N A$ Synthesis, and $q R T-P C R$}

Total RNA, including miRNA, was extracted using the mirVana ${ }^{\mathrm{TM}}$ miRNA Isolation Kit (Ambion). RNA quantity and quality were assessed spectrophotometrically using the Thermo 2000 Bioanalyzer with RNA NanoDrop (Thermo Scientific; http: / www.thermo. com; accessed on 10 September 2021 ). Samples showing A260/A230 ratios of 2.0-2.2 and A260/A280 ratios of 1.8-2.0 were used for further analysis. For quantitative real-time PCR, $1 \mu \mathrm{g}$ of total RNA was reverse transcribed to first-strand cDNA in a final reaction volume of $20 \mu \mathrm{L}$ using the miScript II RT Kit (Qiagen).

The ClmiR86 forward primer was designed based on its mature sequence, and the universal reverse primer was provided with the miScript SYBR Green PCR Kit (Qiagen). 
$\operatorname{miR} 167 \mathrm{c}$ was used as a reference gene to normalize miR86 expression in watermelon and squash [77]. Primers specific to the ClmiR86 precursor were used to detect Pre-miR86 expression levels. Pre-miR86 and ClCIPK5 expression in watermelon was normalized to yellow-leaf-specific protein 8 (ClYLS8) expression. AtUBQ10 was selected as a reference gene for Arabidopsis gene expression [25]. All primer sequences are listed in Table S4.

qRT-PCR was performed on the StepOnePlus ${ }^{\text {TM }}$ Real-Time PCR System (ABI) using the miScript SYBR Green PCR Kit (Qiagen). PCR included pre-incubation at $95^{\circ} \mathrm{C}$ for $15 \mathrm{~min}$, followed by 40 cycles of denaturation at $94{ }^{\circ} \mathrm{C}$ for $15 \mathrm{~s}$, annealing at $55^{\circ} \mathrm{C}$ for $30 \mathrm{~s}$, and extension at $70^{\circ} \mathrm{C}$ for $30 \mathrm{~s}$. Primer amplification specificity and efficiency were measured by melt curve and standard curve analysis, respectively. The relative expression levels were calculated using the $2^{-\Delta \Delta C T}$ method. Each experiment was performed in triplicate.

\subsection{Statistical Analysis}

For the statistical analysis, one-way ANOVA followed by Tukey post hoc test were performed using SPSS Statistics Version 22.

Supplementary Materials: The following are available online at https:/ /www.mdpi.com/article/10 .3390 / plants10102133/s1, Figure S1. Root phenotypes of pho2 mutant under P starvation condition. Figure S2. Expression of CIPK, CBL and PHT genes in transgenic and wild type Arabidopsis. Figure S3. PCR confirmation of ClmiR86 transformation in candidate transgenic Arabidopsis. Table S1. Formula of Hoagland nutrient solution. Table S2. Formula of full-strength MS medium. Table S3. Primers used for vector construction and confirmation of Arabidopsis transformation. Table S4. Gene-specific primers for qRT-PCR.

Author Contributions: Z.H. and M.Z. conceived and designed the study; W.W., H.Z. and Q.D. conducted all experiments and wrote the manuscript; Z.H., J.Y. and W.W. participated in result analyses; H.Y., X.G., R.Q. and P.S. helped perform parts of experiments; all authors reviewed the manuscript. All authors have read and agreed to the published version of the manuscript.

Funding: This research was funded by the National Key Research and Development Plan of China (2019YFD1001904, 2019YFD1000303, 2018YFD0201300), the Natural Science Foundation of Zhejiang Province (LY21C150008), the Earmarked Fund for China Agriculture Research System (CARS-25), the Science and Technology Innovation Platform for Watermelon and Melon Breeding, Reproduction and Spreading of Zhejiang Province (2020-KYY-NSFZ-0314), and the Key Science and Technology Program for Agricultural (Vegetable) New Variety Breeding of Zhejiang Province (2021C02065).

Institutional Review Board Statement: Not applicable.

Informed Consent Statement: Not applicable.

Acknowledgments: The authors thank Huixia Shou of Zhejiang University for donation of the mutant seeds.

Conflicts of Interest: The authors declare no conflict of interest.

\section{References}

1. Liu, N.; Yang, J.H.; Guo, S.G.; Xu, Y.; Zhang, M. Genome-wide identification and comparative analysis of conserved and novel microRNAs in grafted watermelon by high-throughput sequencing. PLoS ONE 2013, 8, e57359. [CrossRef]

2. Schwarz, D.; Öztekin, G.B.; Tüzel, Y.; Brückner, B.; Krumbein, A. Rootstocks can enhance tomato growth and quality characteristics at low potassium supply. Sci. Hortic. 2013, 149, 70-79. [CrossRef]

3. Schwarz, D.; Rouphael, Y.; Colla, G.; Venema, J.H. Grafting as a tool to improve tolerance of vegetables to abiotic stresses: Thermal stress, water stress and organic pollutants. Sci. Hortic. 2010, 127, 162-171. [CrossRef]

4. Bhatt, R.M.; Upreti, K.K.; Divya, M.; Bhat, S.; Pavithra, C.; Sadashiva, A. Interspecific grafting to enhance physiological resilience to flooding stress in tomato (Solanum lycopersicum L.). Sci. Hortic. 2015, 182, 8-17. [CrossRef]

5. Li, H.; Wang, Y.; Wang, Z.; Guo, X.; Wang, F.; Xia, X.; Zhou, J.; Shi, K.; Yu, J.; Zhou, Y. Microarray and genetic analysis reveals that csa-miR159b plays a critical role in abscisic acid-mediated heat tolerance in grafted cucumber plants. Plant Cell Environ. 2016, 39, 1790-1804. [CrossRef]

6. Tateishi, K. Grafting watermelon onto pumpkin. J. Jpn. Hortic. 1927, 39, 5-8. (In Japanese)

7. Sato, N.; Takamatsu, T. Grafting culture of watermelon. Nogyo Sekai. 1930, 25, 24-28. (In Japanese) 
8. Rivero, R.M.; Ruíz, J.M.; Romero, L. Iron Metabolism in Tomato and Watermelon Plants: Influence of Grafting. J. Plant Nutr. 2005, 27, 2221-2234. [CrossRef]

9. Zhang, L.; Meng, X.; Liu, N.; Yang, J.; Zhang, M. Effects of grafting on phosphorus uptake and utilization of watermelon at early stage under low phosphorus stress. J. Fruit Sci. 2012, 29, 120-124.

10. Yetisir, H.; Özdemir, A.E.; Aras, V.; Candır, E.; Aslan, Ö. Rootstocks effect on plant nutrition concentration in different organ of grafted watermelon. Agric. Sci. 2013, 04, 230-237. [CrossRef]

11. Huang, Y.; Jiao, Y.; Nawaz, M.A.; Chen, C.; Liu, L.; Lu, Z.; Kong, Q.; Cheng, F.; Bie, Z. Improving magnesium uptake, photosynthesis and antioxidant enzyme activities of watermelon by grafting onto pumpkin rootstock under low magnesium. Plant Soil 2016, 409, 229-246. [CrossRef]

12. Nawaz, M.A.; Imtiaz, M.; Kong, Q.; Cheng, F.; Ahmed, W.; Huang, Y.; Bie, Z. Grafting: A Technique to Modify Ion Accumulation in Horticultural Crops. Front. Plant Sci. 2016, 7, 1457. [CrossRef] [PubMed]

13. Marschner, H. Mineral Nutrition of Higher Plants, 2nd ed.; Academic Press: London, UK, 1995; p. 889. ISBN 0-12-473543-6.

14. Gilbert, N. Environment: The disappearing nutrient. Nature 2009, 461, 716-718. [CrossRef] [PubMed]

15. Raghothama, K.G. Phosphate acquisition. Annu. Rev. Plant. Physiol. Plant. Mol. Biol. 1999, 50, 665-693. [CrossRef]

16. López-Arredondo, D.L.; Leyva-González, M.A.; González-Morales, S.I.; López-Bucio, J.; Herrera-Estrella, L. Phosphate Nutrition: Improving Low-Phosphate Tolerance in Crops. Annu. Rev. Plant Biol. 2014, 65, 95-123. [CrossRef] [PubMed]

17. Williamson, L.C.; Ribrioux, S.P.; Fitter, A.H.; Leyser, H.O. Phosphate Availability Regulates Root System Architecture in Arabidopsis Plant Physiol. 2001, 126, 875-882. [CrossRef] [PubMed]

18. López-Bucio, J.; Hernández-Abreu, E.; Sánchez-Calderón, L.; Nieto-Jacobo, M.F.; Simpson, J.; Herrera-Estrella, L.R. Phosphate Availability Alters Architecture and Causes Changes in Hormone Sensitivity in the Arabidopsis Root System. Plant Physiol. 2002, 129, 244-256. [CrossRef] [PubMed]

19. Mudge, S.R.; Rae, A.L.; Diatloff, E.; Smith, F.W. Expression analysis suggests novel roles for members of the Pht1 family of phosphate transporters in Arabidopsis. Plant J. 2002, 31, 341-353. [CrossRef] [PubMed]

20. Rouached, H.; Arpat, A.B.; Poirier, Y. Regulation of Phosphate Starvation Responses in Plants: Signaling Players and Cross-Talks. Mol. Plant 2010, 3, 288-299. [CrossRef]

21. Borsani, O.; Zhu, J.; Verslues, P.E.; Sunkar, R.; Zhu, J.-K. Endogenous siRNAs Derived from a Pair of Natural cis-Antisense Transcripts Regulate Salt Tolerance in Arabidopsis. Cell 2005, 123, 1279-1291. [CrossRef]

22. Jones-Rhoades, M.W.; Bartel, D.P.; Bartel, B. MicroRNAs and their regulatory roles in plants. Annu. Rev. Plant Biol. 2006, 57, 19-53. [CrossRef]

23. Sunkar, R.; Chinnusamy, V.; Zhu, J.; Zhu, J.-K. Small RNAs as big players in plant abiotic stress responses and nutrient deprivation. Trends Plant Sci. 2007, 12, 301-309. [CrossRef]

24. Kruszka, K.; Pieczynski, M.; Windels, D.; Bielewicz, D.; Jarmolowski, A.; Szweykowska-Kulinska, Z.; Vazquez, F. Role of microRNAs and other sRNAs of plants in their changing environments. J. Plant Physiol. 2012, 169, 1664-1672. [CrossRef]

25. Pant, B.D.; Buhtz, A.; Kehr, J.; Scheible, W.-R. MicroRNA399 is a long-distance signal for the regulation of plant phosphate homeostasis. Plant J. 2008, 53, 731-738. [CrossRef]

26. Hsieh, L.-C.; Lin, S.-I.; Shih, A.C.-C.; Chen, J.-W.; Lin, W.-Y.; Tseng, C.-Y.; Li, W.-H.; Chiou, T.-J. Uncovering Small RNA-Mediated Responses to Phosphate Deficiency in Arabidopsis by Deep Sequencing. Plant Physiol. 2009, 151, 2120-2132. [CrossRef] [PubMed]

27. Kulcheski, F.R.; Correa, R.; Gomes, I.A.; De Lima, J.C.; Margis, R. NPK macronutrients and microRNA homeostasis. Front. Plant Sci. 2015, 6, 451. [CrossRef]

28. Fujii, H.; Chiou, T.-J.; Lin, S.-I.; Aung, K.; Zhu, J.-K. A miRNA Involved in Phosphate-Starvation Response in Arabidopsis. Curr. Biol. 2005, 15, 2038-2043. [CrossRef]

29. Aung, K.; Lin, S.-I.; Wu, C.-C.; Huang, Y.-T.; Su, C.-L.; Chiou, T.-J. pho2, a Phosphate Overaccumulator, Is Caused by a Nonsense Mutation in a MicroRNA399 Target Gene. Plant Physiol. 2006, 141, 1000-1011. [CrossRef]

30. Bari, R.; Pant, B.D.; Stitt, M.; Scheible, W.-R. PHO2, MicroRNA399, and PHR1 Define a Phosphate-Signaling Pathway in Plants. Plant Physiol. 2006, 141, 988-999. [CrossRef] [PubMed]

31. Chiou, T.-J.; Aung, K.; Lin, S.-I.; Wu, C.-C.; Chiang, S.-F.; Su, C.-L. Regulation of Phosphate Homeostasis by MicroRNA in Arabidopsis. Plant Cell 2006, 18, 412-421. [CrossRef] [PubMed]

32. Batistic, O. Integration and channeling of calcium signaling through the CBL calcium sensor/CIPK protein kinase network. Planta 2004, 219, 915-924. [CrossRef]

33. Cheong, Y.H.; Pandey, G.K.; Grant, J.J.; Batistic, O.; Li, L.; Kim, B.-G.; Lee, S.-C.; Kudla, J.; Luan, S. Two calcineurin B-like calcium sensors, interacting with protein kinase CIPK23, regulate leaf transpiration and root potassium uptake in Arabidopsis. Plant J. 2007, 52, 223-239. [CrossRef]

34. Hu, H.-C.; Wang, Y.-Y.; Tsay, Y.-F. AtCIPK8, a CBL-interacting protein kinase, regulates the low-affinity phase of the primary nitrate response. Plant J. 2009, 57, 264-278. [CrossRef]

35. Vert, G.; Chory, J. A Toggle Switch in Plant Nitrate Uptake. Cell 2009, 138, 1064-1066. [CrossRef] [PubMed]

36. Chen, L.; Ren, F.; Zhou, L.; Wang, Q.-Q.; Zhong, H.; Li, X.-B. The Brassica napus Calcineurin B-Like 1/CBL-interacting protein kinase 6 (CBL1/CIPK6) component is involved in the plant response to abiotic stress and ABA signalling. J. Exp. Bot. 2012, 63, 6211-6222. [CrossRef] [PubMed] 
37. Kim, K.-N.; Cheong, Y.H.; Grant, J.J.; Pandey, G.K.; Luan, S. CIPK3, a Calcium Sensor-Associated Protein Kinase That Regulates Abscisic Acid and Cold Signal Transduction in Arabidopsis. Plant Cell 2003, 15, 411-423. [CrossRef]

38. Pandey, G.K.; Cheong, Y.H.; Kim, K.-N.; Grant, J.J.; Li, L.; Hung, W.; D’Angelo, C.; Weinl, S.; Kudla, J.; Luan, S. The Calcium Sensor Calcineurin B-Like 9 Modulates Abscisic Acid Sensitivity and Biosynthesis in Arabidopsis. Plant Cell 2004, 16, 1912-1924. [CrossRef]

39. Pandey, G.K.; Grant, J.J.; Cheong, Y.H.; Kim, B.-G.; Li, L.G.; Luan, S. Calcineurin-B-Like Protein CBL9 Interacts with Target Kinase CIPK3 in the Regulation of ABA Response in Seed Germination. Mol. Plant 2008, 1, 238-248. [CrossRef]

40. Quan, R.; Lin, H.; Mendoza, I.; Zhang, Y.; Cao, W.; Yang, Y.; Shang, M.; Chen, S.; Pardo, J.M.; Guo, Y. SCABP8/CBL10, a Putative Calcium Sensor, Interacts with the Protein Kinase SOS2 to Protect Arabidopsis Shoots from Salt Stress. Plant Cell 2007, 19, 1415-1431. [CrossRef] [PubMed]

41. Li, L.; Kim, B.-G.; Cheong, Y.H.; Pandey, G.K.; Luan, S. A Ca ${ }^{2+}$ signaling pathway regulates a $\mathrm{K}^{+}$channel for low-K response in Arabidopsis. Proc. Natl. Acad. Sci. USA 2006, 103, 12625-12630. [CrossRef]

42. Xu, J.; Li, H.-D.; Chen, L.-Q.; Wang, Y.; Liu, L.-L.; He, L.; Wu, W.-H. A Protein Kinase, Interacting with Two Calcineurin B-like Proteins, Regulates K+ Transporter AKT1 in Arabidopsis. Cell 2006, 125, 1347-1360. [CrossRef]

43. Ho, C.-H.; Lin, S.-H.; Hu, H.-C.; Tsay, Y.-F. CHL1 Functions as a Nitrate Sensor in Plants. Cell 2009, 138, 1184-1194. [CrossRef] [PubMed]

44. Meng, X.; Liu, N.; Zhang, L.; Yang, J.; Zhang, M. Genotypic differences in phosphorus uptake and utilization of watermelon under low phosphorus stress. J. Plant Nutr. 2014, 37, 312-326. [CrossRef]

45. Kim, K.-N.; Cheong, Y.H.; Gupta, R.; Luan, S. Interaction Specificity of Arabidopsis Calcineurin B-Like Calcium Sensors and Their Target Kinases. Plant Physiol. 2000, 124, 1844-1853. [CrossRef]

46. Albacete, A.; Martínez-Andújar, C.; Ghanem, M.E.; Acosta, M.; Sánchez-Bravo, J.; Asins, M.J.; Cuartero, J.; Lutts, S.; Dodd, I.C.; Pérez-Alfocea, F. Rootstock-mediated changes in xylem ionic and hormonal status are correlated with delayed leaf senescence, and increased leaf area and crop productivity in salinized tomato. Plant, Cell Environ. 2009, 32, 928-938. [CrossRef]

47. Huang, Y.; Li, J.; Hua, B.; Liu, Z.; Fan, M.; Bie, Z. Grafting onto different rootstocks as a means to improve watermelon tolerance to low potassium stress. Sci. Hortic. 2013, 149, 80-85. [CrossRef]

48. Zeng, H.; Wang, G.; Hu, X.; Wang, H.; Du, L.; Zhu, Y. Role of microRNAs in plant responses to nutrient stress. Plant Soil 2014, 374, 1005-1021. [CrossRef]

49. Wang, J.-W.; Wang, L.-J.; Mao, Y.-B.; Cai, W.-J.; Xue, H.-W.; Chen, X.-Y. Control of Root Cap Formation by MicroRNA-Targeted Auxin Response Factors in Arabidopsis. Plant Cell 2005, 17, 2204-2216. [CrossRef]

50. Gifford, M.L.; Dean, A.; Gutierrez, R.A.; Coruzzi, G.M.; Birnbaum, K.D. Cell-specific nitrogen responses mediate developmental plasticity. Proc. Natl. Acad. Sci. USA 2008, 105, 803-808. [CrossRef]

51. Vidal, E.; Araus, V.; Lu, C.; Parry, G.; Green, P.J.; Coruzzi, G.M.; Gutierrez, R.A. Nitrate-responsive miR393/AFB3 regulatory module controls root system architecture in Arabidopsis thaliana. Proc. Natl. Acad. Sci. USA 2010, 107, 4477-4482. [CrossRef]

52. Wang, L.; Mai, Y.-X.; Zhang, Y.-C.; Luo, Q.; Yang, H.-Q. MicroRNA171c-Targeted SCL6-II, SCL6-III, and SCL6-IV Genes Regulate Shoot Branching in Arabidopsis. Mol. Plant 2010, 3, 794-806. [CrossRef]

53. Zhao, M.; Ding, H.; Zhu, J.-K.; Zhang, F.; Li, W. Involvement of miR169 in the nitrogen-starvation responses in Arabidopsis. New Phytol. 2011, 190, 906-915. [CrossRef]

54. Liang, G.; He, H.; Yu, D. Identification of Nitrogen Starvation-Responsive MicroRNAs in Arabidopsis thaliana. PLoS ONE 2012, 7, e48951. [CrossRef]

55. He, H.; Liang, G.; Li, Y.; Wang, F.; Yu, D. Two Young MicroRNAs Originating from Target Duplication Mediate Nitrogen Starvation Adaptation via Regulation of Glucosinolate Synthesis in Arabidopsis thaliana. Plant Physiol. 2014, 164, $853-865$. [CrossRef] [PubMed]

56. Yan, Y.; Wang, H.; Hamera, S.; Chen, X.; Fang, R. miR444a has multiple functions in the rice nitrate-signaling pathway. Plant J. 2014, 78, 44-55. [CrossRef] [PubMed]

57. Okumura, S.; Mitsukawa, N.; Shirano, Y.; Shibata, D. Phosphate Transporter Gene Family of Arabidopsis thaliana. DNA Res. 1998, 5, 261-269. [CrossRef] [PubMed]

58. Poirier, Y.; Thoma, S.; Somerville, C.; Schiefelbein, J. Mutant of Arabidopsis Deficient in Xylem Loading of Phosphate. Plant Physiol. 1991, 97, 1087-1093. [CrossRef] [PubMed]

59. Hamburger, D.; Rezzonico, E.; Macdonald-Comber Petetot, J.; Somerville, C.; Poirier, Y. Identification and characterization of the Arabidopsis PHO1 gene involved in phosphate loading to the xylem. Plant. Cell 2002, 14, 889-902. [CrossRef] [PubMed]

60. Kant, S.; Peng, M.; Rothstein, S.J. Genetic Regulation by NLA and MicroRNA827 for Maintaining Nitrate-Dependent Phosphate Homeostasis in Arabidopsis. PLoS Genet. 2011, 7, e1002021. [CrossRef]

61. Huang, T.-K.; Han, C.-L.; Lin, S.-I.; Chen, Y.-J.; Tsai, Y.-C.; Chen, Y.-R.; Chen, J.-W.; Lin, W.-Y.; Chen, P.-M.; Liu, T.-Y.; et al. Identification of Downstream Components of Ubiquitin-Conjugating Enzyme PHOSPHATE2 by Quantitative Membrane Proteomics in Arabidopsis Roots. Plant Cell 2013, 25, 4044-4060. [CrossRef]

62. Park, B.S.; Seo, J.S.; Chua, N.-H. Nitrogen limitation adaptation recruits phosphate2 to Target the Phosphate Transporter PT2 for Degradation during the Regulation of Arabidopsis Phosphate Homeostasis. Plant Cell 2014, 26, 454-464. [CrossRef]

63. Li, C.; Yu, X.; Bai, L.; He, C.; Li, Y. Responses of miRNAs and their target genes to nitrogen- or phosphorus-deficiency in grafted cucumber seedlings. Hortic. Environ. Biotechnol. 2016, 57, 97-112. [CrossRef] 
64. Weinl, S.; Kudla, J. The CBL-CIPK Ca 2+-decoding signaling network: Function and perspectives. New Phytol. 2009, 184, 517-528. [CrossRef] [PubMed]

65. Qiu, Q.-S.; Guo, Y.; Dietrich, M.A.; Schumaker, K.S.; Zhu, J.-K. Regulation of SOS1, a plasma membrane Na+/H+ exchanger in Arabidopsis thaliana, by SOS2 and SOS3. Proc. Natl. Acad. Sci. USA 2002, 99, 8436-8441. [CrossRef] [PubMed]

66. Shi, H.; Quintero, F.J.; Pardo, J.M.; Zhu, J.-K. The Putative Plasma Membrane Na+/H+ Antiporter SOS1 Controls Long-Distance $\mathrm{Na}+$ Transport in Plants. Plant Cell 2002, 14, 465-477. [CrossRef] [PubMed]

67. Tang, R.-J.; Zhao, F.-G.; Garcia, V.; Kleist, T.J.; Yang, L.; Zhang, H.-X.; Luan, S. Tonoplast CBL-CIPK calcium signaling network regulates magnesium homeostasis in Arabidopsis. Proc. Natl. Acad. Sci. USA 2015, 112, 3134-3139. [CrossRef] [PubMed]

68. Léran, S.; Edel, K.H.; Pervent, M.; Hashimoto, K.; Corratgé-Faillie, C.; Offenborn, J.N.; Tillard, P.; Gojon, A.; Kudla, J.; Lacombe, B. Nitrate sensing and uptake in Arabidopsisare enhanced by ABI2, a phosphatase inactivated by the stress hormone abscisic acid. Sci. Signal. 2015, 8, ra43. [CrossRef]

69. Tripathi, V.; Parasuraman, B.; Laxmi, A.; Chattopadhyay, D. CIPK6, a CBL-interacting protein kinase is required for development and salt tolerance in plants. Plant J. 2009, 58, 778-790. [CrossRef] [PubMed]

70. Kolukisaoglu, U.; Weinl, S.; Blazevic, D.; Batistic, O.; Kudla, J. Calcium Sensors and Their Interacting Protein Kinases: Genomics of the Arabidopsis and Rice CBL-CIPK Signaling Networks. Plant Physiol. 2004, 134, 43-58. [CrossRef]

71. Ying, Y.; Yue, W.; Wang, S.; Li, S.; Wang, M.; Zhao, Y.; Wang, C.; Mao, C.; Whelan, J.; Shou, H. Two h-Type Thioredoxins Interact with the E2 Ubiquitin Conjugase PHO2 to Fine-Tune Phosphate Homeostasis in Rice. Plant Physiol. 2017, 173, 812-824. [CrossRef]

72. Curtis, M.D.; Grossniklaus, U. A Gateway Cloning Vector Set for High-Throughput Functional Analysis of Genes in Planta. Plant Physiol. 2003, 133, 462-469. [CrossRef] [PubMed]

73. Clough, S.J.; Bent, A.F. Floral dip: A simplified method for Agrobacterium-mediated transformation of Arabidopsis thaliana. Plant J. 1998, 16, 735-743. [CrossRef]

74. Thompson, J.D.; Gibson, T.J.; Plewniak, F.; Jeanmougin, F.; Higgins, D.G. The CLUSTAL_X windows interface: Flexible strategies for multiple sequence alignment aided by quality analysis tools. Nucleic Acids Res. 1997, 25, 4876-4882. [CrossRef]

75. Chapman, H.D.; Pratt, P.F. Phosphorus. Methods of Analysis for Soils, Plants and Waters; University of California: Berkeley, CA, USA, 1961; pp. 160-170.

76. Siddiqi, M.Y.; Glass, A.D. Utilization index: A modified approach to the estimation and comparison of nutrient utilization efficiency in plants. J. Plant Nutr. 1981, 4, 289-302. [CrossRef]

77. Wu, W.; Deng, Q.; Shi, P.; Yang, J.; Hu, Z.; Zhang, M. Identification of Appropriate Reference Genes for Normalization of miRNA Expression in Grafted Watermelon Plants under Different Nutrient Stresses. PLoS ONE 2016, 11, e0164725. [CrossRef] [PubMed] 